\title{
Saúde Pública e Sociedade de Risco(*)
}

\author{
PUBLIC HEALTH AND RISK SOCIETY
}

Aurea Maria Zöllner Ianni ${ }^{(\star \star)}$

\section{RESUMO}

O presente trabalho apresenta uma síntese sobre o conceito de sociedade de risco, formulada por Ulrich Beck, o principal autor nesse campo da teoria social contemporânea, estabelecendo correlações desta nova etapa da sociedade moderna com questões enfrentadas pela saúde pública. A sociedade de risco emerge no contexto da modernização reflexiva em que a sociedade industrial entra numa etapa de autoconfrontação, ou seja, os riscos são produzidos pelas certezas da sociedade industrial: o pensamento, a ação das pessoas, as instituições. As políticas públicas, neste contexto, e dentre elas as de saúde pública, não permanecem ilesas ao processo de produção sistemática, residual e multiplicadora de riscos e perigos, explícitos e silenciosos. Este fenômeno coloca aos profissionais do campo da saúde, sociedade civil, formuladores de políticas e legisladores o desafio da construção de pactos de segurança considerando esse novo cenário da modernidade industrial.

\section{Palavras-chave}

Modernidade Reflexiva; Saúde Pública; Sociedade de Risco.

\section{ABSTRACT}

This work is a synthesis about the concept of risk society proposed by Ulrich Beck, the main author in this field of contemporary social theory, esta-

(*) Artigo baseado em apresentação realizada durante o VII Seminário Internacional de Direito Sanitário, São Paulo, 13 a 15 de setembro de 2006. Recebido em 21.12.6 Aprovado em 8.6.7.

${ }^{* \star}$ ) Pesquisadora Científica do Instituto de Saúde SESSP e Docente da Faculdade de Ciências Médicas da Santa Casa de São Paulo. E-mail: <aureanni@saude.sp.gov.br>. 
blishing correlations between this new stage of the modern society and issues faced by public health. The risk society emerges in the context of reflexive modernization, in which the industrial society enters a new stage of self confrontation, $i$. e., the risks are generated by the certainties of the industrial society: people's actions and thinking and institutions. Public politics in this context among them public health politics - are affected by this systematics and multiplying production process of explicit and silent risks and dangers. Within this phenomenon health professionals, civil society and whose formulates politics and laws are faced to the challenge of construction of security agreements considering this new scenery of industrial modernity.

\section{Key words}

Public Health; Reflexive Modernity; Risk Society.

\section{INTRODUÇÃO}

Novas doenças e epidemias, moléstias crônicas e incuráveis. Estes problemas de saúde vêm desafiando as sociedades, o conhecimento. Parece que há uma descoberta a cada ano de um novo vírus, uma nova bactéria; novas e diferentes causas de doenças conhecidas. O campo da saúde pública, em suas várias disciplinas, tem, evidentemente, trabalhado exaustivamente a problemática da emergência, reemergência e permanescência(1) das doenças e suas raízes etiológicas, sociais, ambientais e ecológicas.

Grande parte dessa produção, no entanto, tem se ocupado desses impactos e suas conseqüências para a vida humana, suas intercorrências na saúde das populações. Um exemplo é a discussão sobre o comportamento dos microorganismos nas novas cadeias ecológicas desencadeadas pela intervenção humana; é o caso do príon causador da doença da 'vacalouca', uma alteração antropogênica, introduzida pelo homem na cadeia alimentar bovina, a partir da introdução de proteína animal no cardápio do gado confinado.

Mesmo quando se discutem os vírus e bactérias hiper-resistentes, muitos deles resultantes das ações de depleção do ambiente, de invasão de nichos ecológicos, da bioengenharização intensiva de seres vegetais e animais, das práticas iatrogênicas na medicina etc., a ênfase do debate é sempre na detecção dessas alterações e as estratégias de controle e/ou erradicação das

(1) BARRETO, Maurício Lima. A Epidemiologia, sua história e crises: notas para pensar o futuro. In: COSTA, Dina Czeresnia (Org.) Epidemiologia: teoria e objeto. São Paulo: HUCITEC-ABRASCO, 1990. p. $19-38$. 
doenças; o foco é, sempre, dirigido à avaliação dos impactos desses organismos na saúde humana e seus decorrentes enfrentamentos posteriores.

A saúde pública pouco tem se detido sobre uma questão anterior à ocorrência desses fenômenos, ou seja, quais estratégias adotar, como conduzir processos que evitem esses eventos e suas conseqüências, ou ainda, como intervir nos processos de forma a que esses perigos e riscos sejam os menos devastadores possíveis. Claro que a pesquisa e as ações em saúde pública estão atentas aos efeitos colaterais de substâncias, procedimentos e práticas adotadas. No entanto, esses efeitos emergem aqui e ali, insistindo desafiar os prognósticos, a previsibilidade experimental e estatística dos ensaios clínico-laboratoriais. Isto quer dizer que a saúde pública trabalha ainda, e fortemente, dentro dos marcos da capacidade reflexiva da modernidade (reflexiva no sentido de refletir, tomar consciência, examinar o entendimento), em que a idéia de progresso condiciona o desenvolvimento científico e tecnológico, na qual esse conhecimento é compreendido como essencialmente cumulativo - cada etapa superando a anterior, numa progressiva expansão. Este é o marco que se denomina de etapa reflexiva da modernização da sociedade capitalista que acredita que mais reflexão sobre os problemas, conhecimento especializado, ciência e tecnologia criam, necessariamente, possibilidades melhores ${ }^{(2)}$ - para as pessoas e nações e, conseqüentemente, melhores condições de saúde para as populações.

Reconhecer que se atua, ainda e hegemonicamente, dentro desses marcos da modernidade é de importância fundamental, porque muitas das estratégias de enfrentamento das doenças implementadas pela saúde pública reproduzem processos que estão na origem dos fenômenos da emergência, recrudescência e permanescência das doenças. É o caso, já 'clássico' e recorrentemente discutido, do uso indevido de antibióticos em seres humanos e na alimentação de animais para consumo humano, com a intercorrência de bactérias hiper-resistentes ${ }^{(3)}$. Não se trata apenas de descontrole na utilização dos produtos mas, também, da introdução acelerada de novas e novas 'gerações' de medicamentos/substâncias que provocam mutações e hiper-resistência dos microorganismos; processo evolutivo potencializado pela produção biotecnológica e pelas práticas de saúde. O que dizer sobre as estratégias de combate aos vetores - como o aedes aegypti, por exemplo - que, além de terem resultado numa erradicação fictícia, demonstrando a incapacidade de se atingir soluções permanentes como originalmente se acreditava, abriu flancos para a introdução do dengue 2, doença hemorrágica, de manifestação mais grave ${ }^{(4)}$ ? E das práticas de imunização, por exem-

(2) BECK, Ulrich. A reinvenção da política: rumo a uma teoria da modernização reflexiva. In: GIDDENS, Antony; BECK, Ulrich; LASH, Scot. op. cit.

(3) POSSAS, Cristina A. Social ecosystem health: confronting the complexity and emergence of infectious diseases. Cadernos de Saúde Pública, Rio de Janeiro, v. 17, n. 1, p. 31-41, jan./fev. 2001. (4) BUSS, Paulo Marchiori. Globalization and disease: in an unequal world, unequal health. Cadernos de Saúde Pública, Rio de Janeiro, v. 18, n. 6, p. 1783-1788, nov./dez. 2002. 
plo, por meio das quais disseminam-se toneladas de microorganismos (atenuados ou geneticamente modificados) em extensas camadas da população humana de diferentes faixas etárias, sexo e etnia, em grandes domínios territoriais, inserindo-os em inúmeras cadeias tróficas, ambientais?

Desafios como esses evidenciam que mais conhecimento, técnica e especialização têm contribuído para o seu inverso, a permanência e desenvolvimento de perigos e riscos, numa cadeia que teve seu início na esfera da 'natureza' e hoje se constitui intrinsecamente social e amplamente produzida e reproduzida na esfera do social. A saúde pública tem sido, nesse sentido, uma prática intensiva de colonização da natureza. Este é um dos aspectos que diz respeito à etapa reflexiva da modernização, correspondendo porém, e simultaneamente, a uma nova etapa da sociedade industrial tardia, a da reflexividade da modernidade, etapa esta em que vai se configurar a sociedade de risco global.

\section{SAÚDE, REFLEXIVIDADE E RISCO NA SOCIEDADE GLOBAL}

A reflexividade é o estágio supremo do poder esclarecido triunfante sobre a Terra, a natureza e os homens. Aqui, o projeto da sociedade industrial entra em sua etapa autodestrutiva, na qual o êxito das modernizações já não transcorre dentro das vias e categorias da sociedade, mas sim contra elas. As ameaças da vida, na sociedade industrial, metamorfoseiam-se em perigo; há uma globalidade da contaminação e das cadeias mundiais de alimentos e de produtos, o clima é envenenado, regras da vida cotidiana são reviradas; domina a carência sobre a abundância, os tratamentos médicos fracassam, os edifícios da racionalidade científica vêm abaixo, os governos também. Entra em colapso a idéia de controle, de certeza e de segurança ${ }^{(5)}$.

A sociedade reflexiva é sociedade de risco porque no centro das preocupações, e inversamente à lógica da produção e distribuição da riqueza que até recentemente determinara o pensamento social, passam a figurar os perigos e as conseqüências dessa modernização que vão sendo plasmados como ameaças irreversíveis às plantas, animais e seres humanos.

Perigos ou riscos no contexto da sociedade de risco global, diz Beck(6), não são opções que podem ser escolhidas ou rejeitadas no curso do debate político (aqui compreendido em sentido ampliado, para além da esfera estritamente política, envolvendo os domínios social, técnico-científico, das organizações sociais e da mídia, entre outros). Ao contrário, o risco é uma condição estrutural do avanço da industrialização, onde a produção de perigos mina ou anula o

(5) BECK, Ulrich. La sociedad del riesgo global. Madrid: Siglo Veintiuno de España Editores, 2002.

(6) ADAM, Bárbara; BECK, Ulrich; LOON, Joost van (Eds.) The risk society and beyond: critical issues for social theory. London, Thousand Oaks, New Delhi: SAGE Publications, 2000. p. 1-32. 
estado de segurança constituído pela previsibilidade estabelecida no sistema de cálculos dos riscos, no sistema de proteção e seguridade social.

Risco é o enfoque moderno da previsão e controle das conseqüências futuras da ação humana, das diversas conseqüências indesejáveis da modernidade. Importante neste conceito é que o dano possível pode ser contingente, isto é, evitável (7). O conceito de risco é um intento institucionalizado de colonizar o futuro(8); "risco surge como conceito quando o futuro passa a ser entendido como passível de controle" ${ }^{*}$. Na etapa reflexiva da modernidade, a colonização do futuro presentifica-se, instaurando-se por meio das práticas produtivas, comunicativas, técnico-administrativas e científicas da sociedade. O risco, generalizado e expandido, é simultaneamente probabilidade e realidade.

Toda sociedade já enfrentou perigos, mas na sociedade de risco o perigo está articulado com os processos técnicos, científicos e administrativos, por isso eles não se manifestam de forma restrita; são globais. As teorias, instrumentos e medidas até então utilizados para avaliar e controlar os riscos, tornam-se cada vez mais superados.

Os riscos têm dimensão global; muitas vezes, porém, com manifestação local. Vários deles são imperceptíveis, tornando-se evidentes apenas em estágios já avançados; seus efeitos nocivos são incalculáveis e imprevisíveis. Estes fatores tornam os mecanismos e instrumentos construídos pela sociedade insuficientes para a identificação e controle dos perigos.

Assim, tal processo causa confusão de categorias: as mesmas substâncias nocivas podem ter um significado completamente diferente para pessoas diferentes, o que pode ser 'não perigoso' em relação a um produto específico, talvez seja extremamente perigoso a um consumidor na cadeia final, aquele no qual o ser humano se converteu no atual estágio de comercialização mundial. Exemplo na Saúde é o consumo de medicamentos que provocam reações e conseqüências variadas conforme quem os utiliza, a idade, a etnia, o gênero, as condições biofísicas individuais etc. Nessa dinâmica, a avaliação dos perigos remete ao 'não saber' e as conexões de causalidade e não podem ser perseguidas; a sociedade industrial de risco dissolve-se, assim, no território da insegurança.

A saúde não permanece ilesa a esse processo. Aí também se verifica a reflexividade da sociedade, aí também a sociedade de risco global encontra expressão. Mais do que isso, a saúde pública informa a sociedade sobre o risco por meio da epidemiologia. Segundo Carmo(10), o "Risco epidemiológi-

(7) LUHMANN, Niklas. El concepto de riesgo. In Sociología del riesgo. México: Universidad Iberoamericana; Triana Ed., 1998. p 43-76.

(8) BECK, Ulrich. La sociedad del riesgo global, cit.

(9) LUIZ, Olinda do Carmo; COHN, Amélia. Sociedade de risco e risco epidemiológico. Cadernos de Saúde Pública, Rio de Janeiro, v. 22, n. 11, p. 4. Disponível em: <http://www.scielo.br/scielo.php>. Acesso em: $11 \mathrm{dez} .2006$.

(10) Id. Ibid., p. 6. 
co pode ser definido como a probabilidade de ocorrência de um determinado evento relacionado à saúde, estimado a partir do que ocorreu no passado". Disciplina própria do campo da saúde pública e estruturante de suas práticas e conhecimentos, a Epidemiologia ${ }^{(11)}$ amplia sua atuação no vasto campo da Saúde mediante o conceito de risco, exaustivamente incorporado pela denominada epidemiologia clínica(12). "É a epidemiologia que informa sobre quais são os fatores de risco: a comida gordurosa, as tentações ricas em colesterol, a fumaça do cigarro."(13)

Nesse sentido, a saúde pública se vê totalmente comprometida e enredada na sociedade de risco global.

\section{O RISCO NAS SOCIEDADES MODERNAS}

A obra de Ulrich Beck(14) é referência no tema, pois foi este autor quem formulou, de maneira mais profunda e ampla, esse conceito. Complementarmente, incorporam-se na análise as obras de Guiddens ${ }^{(15))}$ e Lash $^{(16)}$, produções também expressivas nesse campo da teoria social.

A fim de esclarecer o contexto em que emerge a sociedade de risco global, Ulrich Beck(17) explicita o que, para ele, distingue a primeira da segunda modernidade. O primeiro termo, segundo o autor, refere-se à modernidade baseada nas sociedades dos Estados-nação, em que as relações, as redes sociais e as comunidades se entendem em um sentido essencialmente territorial. Voltadas para a produção de riquezas, as pautas coletivas de vida dessa primeira modernidade são o progresso, a controlabilidade, o pleno emprego e a exploração da natureza, numa perspectiva em que os riscos advindos dessas práticas podem ser (e são) auto-impingidos à sociedade, podendo manter-se, no entanto, sob controle, pois podem ser substi-

(11) FORATTINI, Osvaldo Paulo. Epidemiologia geral. Porto Alegre: Artes Médicas, 1986. CASTELLANOS, Pedro Luis. Epidemiologia, saúde pública, situação de saúde e condições de vida: considerações conceituais. In: BARATA, Rita Barradas. (Org.) Condições de vida e situação de saúde. Rio de Janeiro: ABRASCO, 1997. p. 31-75.

(12) BARATA, Rita Barradas. Epidemiologia clínica: nova ideologia médica? Cadernos de Saúde Pública, São Paulo, v. 12, 199. p 555-560.

(13) LUIZ, Olinda do Carmo. op. cit., p. 10.

(14) BECK, Ulrich. La sociedad del riesgo: hacia uma nueva modernidad. Barcelona-Buenos AiresMéxico: Paidós, 1998.

BECK, Ulrich. La sociedad del riesgo global, cit.

BECK, Ulrich. A reinvenção da política: rumo a uma teoria da modernização reflexiva, cit. e Autodissolução e auto-risco da sociedade industrial: o que isso significa? In: GIDDENS, Antony; BECK, Ulrich; LASH, Scot. op. cit., p. 11-71 e 207-218.

(15) GIDDENS, Antony. A vida em uma sociedade pós-tradicional. In: GIDDENS, Antony; BECK, Ulrich; LASH, Scot. op. cit., p. 73-133.

(16) LASH, Scott. A reflexividade e seus duplos: estrutura, estética, comunidade. In: GIDDENS, Antony; BECK, Ulrich; LASH, Scot. op. cit. p. 135-206.

(17) BECK, Ulrich. Autodissolução e auto-risco da sociedade industrial: o que isso significa?, cit. 
tuídos pela automodificação. Os parâmetros dos cálculos, da previsibilidade, da riqueza e do conhecimento técnico-científico dão à sociedade uma confiança no progresso e na resolução dos problemas de toda ordem postos por esse desenvolvimento. Há uma crença no controle assentada sobre a racionalidade.

A segunda modernidade - de acordo com o próprio $B e c k^{(18)}$, citando diferentes autores: pós-modernidade, modernidade industrial tardia, era global, constelação pós-nacional etc. - é uma modernidade radicalizada, em que a idéia de controlabilidade, de certeza ou segurança, é solapada.

"Duas fases podem ser aqui distinguidas: primeiro, um estágio em que os efeitos e as auto-ameaças são sistematicamente produzidos, mas não se tornam questões públicas ou o centro dos conflitos políticos. Aqui, o autoconceito da sociedade industrial ainda predomina, tanto multiplicando como "legitimando" as ameaças produzidas por tomadas de decisão, como "riscos residuais" (a "sociedade de risco residual").

Segundo, uma situação completamente diferente surge quando os perigos da sociedade industrial começam a dominar os debates e conflitos públicos, tanto políticos como privados. Nesse caso, as instituições da sociedade industrial tornam-se os produtores e legitimadores das ameaças que não conseguem controlar. O que acontece aqui é que alguns aspectos da sociedade industrial tornam-se social e politicamente problemáticos. Por um lado, a sociedade ainda toma decisões e realiza ações segundo o padrão da velha sociedade industrial, mas, por outro, o sistema judicial e a política são obscurecidos por debates e conflitos que se originam do dinamismo da sociedade de risco." (19)

É neste contexto que se estabelece o que se denomina de sociedade de risco global. Enfoque moderno da previsibilidade e do controle das conseqüências futuras da ação humana, ou das diversas conseqüências não desejadas da modernização radicalizada, o risco se expande para além desses limites, penetrando todos os processos sociais. É quando o risco se torna protagonista da sociedade.

Algumas características constitutivas da sociedade de risco podem ser apresentadas como estruturantes desse novo momento que se vive:

- A construção do risco é sumamente social. Essa construção se dá não apenas pela articulação e divulgação do conhecimento técnicocientífico, mas numa rede de produção da percepção dos riscos: o universo científico, a mídia (impressa, eletrônica, televisiva), os grupos sociais organizados, a grande política, o senso comum. O mapa do risco é um mapa cognitivo sobre incertezas fabricadas. ${ }^{(20)}$

(18) Id. Ibid.

(19) Id. Ibid. p. 15.

(20) Id. La sociedad del riesgo: hacia uma nueva modernidad, cit. 
- Os riscos constituem uma produção sistemática da sociedade. O avanço da sociedade expresso nas diferentes políticas e práticas sociais, no desenvolvimento econômico e científico, no conjunto do conhecimento, conduz a uma resolução dos problemas, dos riscos; porém, e simultaneamente, cria novos problemas e novos riscos. As incertezas são fabricadas; maior êxito, maiores os riscos. Há uma autogeração dos riscos, das incertezas, numa progressiva colonização do futuro.

- Os riscos são residuais ou, dito de outra forma, produzem e reproduzem efeitos colaterais. A crença na infalibilidade tecnológica desmorona, ou é refutada, diante do próximo acidente, do próximo perigo. A proteção diminui à medida que aumenta o perigo. Os riscos são cada vez mais imprevisíveis, imperceptíveis, incalculáveis. Funda-se, então, uma ambigüidade: desenvolvem-se estratégias para evitar os riscos a partir de riscos criados e desenvolvidos pela própria sociedade. Enfrentamse os riscos com os mesmos instrumentos que os potencializaram.

- Os riscos se multiplicam. Expandem-se, muitas vezes silenciosamente, rompendo fronteiras de tempo-espaço, normalidade-anormalidade, calculável-incalculável, específico-inespecífico, material-imaterializado, tolerável-intolerável. As conjecturas de causalidade são subtraídas.

Neste contexto, se estabelece uma ambivalência: como traçar limites entre os danos? Como traçar limites entre o aceitável e o inaceitável? Qual a capacidade de suporte dos ecossistemas, das populações para suportar perigos?

A sociedade torna-se, então, reflexiva, quer dizer, preocupada com suas conseqüências não desejadas. Os riscos já não são um problema exterior às pessoas, às políticas, à economia, ao ambiente, à saúde - mas institucionalizados, quase-sujeitos, e a utopia da modernidade industrial tardia é a eliminação dos riscos (contrariamente à primeira modernidade em que a utopia da sociedade era o fim da escassez).

Nesta segunda modernidade, segundo $B e c k^{(21)}$, são as regras, as instituições e as capacidades específicas que estruturam a identificação e avaliação do risco em contextos culturais específicos. Estas são as matrizes de poder legal, epistemológico e cultural em que se desenvolve a política do risco. É como se, nessa modernidade, a sociedade tivesse que navegar numa espécie de "irresponsabilidade organizada", num constante jogo de poder das definições do risco. São essas relações que vão estabelecer as definições do que seja ou não risco. $B e c k^{(22)}$ sintetiza em quatro questões os problemas com os quais a sociedade contemporânea se defronta:

(21) BECK, Ulrich. La sociedad del riesgo global, cit.

(22) Id. Ibid., p. 237. 
1. "Quem tem que definir e determinar a inocuidade de produtos, de perigo, dos riscos? Quem tem a responsabilidade: quem gera os riscos, quem se beneficia deles, quem se vê potencialmente afetado por eles ou os organismos públicos?

2. Que tipo de conhecimento ou desconhecimento sobre as causas, dimensões, atores, etcétera está implicado? A quem se tem que submeter as evidências e 'provas'?

3. $O$ que se deve considerar como prova suficiente em um mundo no qual o conhecimento sobre os riscos ambientais ${ }^{(23)}$ é necessariamente discutido e probabilista?

4. Quem tem que decidir sobre a compensação para os afetados, e quê constituem formas adequadas de limitação, controle e regulação dos danos futuros?" (tradução da Autora)

\section{CONCLUSÕES - PARA UM NOVO PACTO DE SEGURANÇA}

O grau de fluidez e insegurança com que se defronta a sociedade faz com que ela se torne crítica de si mesma. Vive-se um momento em que está posta em xeque a própria estrutura sobre a qual a sociedade se movimenta.

Lash(24), concordando com Beck, propõe sua inquietação: "O que acontece quando a modernização, compreendendo seus próprios excessos e espirais viciosas de subjugação destrutiva (de natureza interior, exterior $e$ social), começa a se assumir como objeto de reflexão?"

Este é o ponto de encontro dos autores que hoje discutem a sociedade de risco, encontrar, na dinâmica societária geral, as características, ações, relações e sinais de respostas das sociedades a esse novo desafio.

Um primeiro impasse surge e, diante de questões como essas, as sociedades ainda se apresentam engessadas num vocabulário, num 'repertório' cultural, particularmente inadequado, não apenas no que se refere às catástrofes modernas, como também com relação aos objetivos criados pelas incertezas fabricadas. Conseqüentemente, emerge um paradoxo: ao mesmo tempo em que se percebe que perigos e ameaças tornam-se cada vez mais óbvios e perigosos, a dificuldade em atingir o intento de estabelecer provas, atribuições e indenizações é cada vez maior, considerados os meios científicos, legais e políticos estabelecidos.

Este paradoxo remete a outra indagação: quem é o sujeito político da sociedade de risco? Beck ${ }^{(25)}$ sustenta que são todos e ninguém, na medida em que os perigos e riscos são quase-sujeitos, ou seja, são 'atores' dessa

(23) E os de saúde também (induzidos pelas práticas biotecnológicas, pelo consumo/exposição a agentes químicos, ondas eletromagnéticas etc.).

(24) LASH, Scott. op. cit., p. 128.

(25) BECK, Ulrich. La sociedad del riesgo global, cit. 
nova modernidade; um ator poderoso e incontrolável que deslegitima e desestabiliza as instituições estatais com responsabilidades em matéria de controle de contaminações, em particular, e da segurança pública, em geral.

Como o risco torna-se um importante protagonista das relações sociais, a sociedade se converte em problema e questão para ela mesma; por conseguinte é uma sociedade extremamente autocrítica e de autoconfrontação. Por isso, e nesse sentido, a sociedade de risco é sumamente política num sentido novo. Na segunda modernidade, a privacidade contém a sociedade mundial, o local, o global; o que era apolítico torna-se político. Neste contexto, vai emergindo uma nova cultura, a de uma sociedade extremamente política, pois diante do potencial de catástrofes a ação política é absolutamente vital, e agora essa ação política está inevitavelmente inscrita nas decisões sobre a vida e a morte ${ }^{(26)}$. É esta radicalização da política, segundo $B e c k^{27)}$, que exige da sociedade novos pactos, novos acordos, novas regras, novas institucionalidades.

Em saúde, pode-se dizer da necessidade de um novo pacto de 'segurança', uma nova construção social. Para esta construção, alguns elementos devem ser considerados:

- a sociedade tem que ser altamente interpretativa, no sentido de definir quais são os riscos e de torná-los visíveis;

- deve ocorrer uma desmonopolização dos saberes para além das instâncias já estabelecidas. Deve-se reconhecer que o conhecimento do risco se dá na intersecção das esferas científica, das instituições, dos movimentos sociais, da mídia entre outras;

- pactos de segurança devem pressupor a colisão dos discursos, múltiplos e diversificados, numa construção em redes locais, regionais e globais.

Trata-se, portanto, da constituição de uma sociedade essencialmente argumentativa, que entende a força metódica de suas dúvidas, ampliando sempre a corrente de resultados - parciais, inseguros, desconexos e possíveis. Como diria Haraway ${ }^{(28)}$, uma sociedade que enfrenta "o prazer da confusão de fronteiras e a responsabilidade de sua construção".

\section{REFERÊNCIAS BIBLIOGRÁFICAS}

ADAM, Bárbara e LOON, Joost van. Introduction: repositioning ris; the challenge for social theory. In: ADAM, Bárbara, BECK, Ulriche; LOON, Joost van (Eds.) The risk society and beyond: critical issues for social theory. London, Thousand Oaks, New Delhi: SAGE Publications, 2000.

(26) ADAM, Bárbara; LOON, Joost van. op. cit.

(27) BECK, Ulrich. La sociedad del riesgo global, cit.

(28) HARAWAY, Donna. Simians, cyborgs and women: the reinvention of nature. London: Free Association Books. 1991. Cit. In BECK, Ulrich. La sociedad del riesgo global, cit. p. 43. 
BARATA, Rita Barradas. Epidemiologia clínica: nova ideologia médica? Cadernos de Saúde Pública, São Paulo, v.12, 1996. p 555-560.

BARRETO, Maurício Lima. A Epidemiologia, sua história e crises: notas para pensar o futuro. In: COSTA, Dina Czeresnia (Org.) Epidemiologia: teoria e objeto. São Paulo: HUCITEC-ABRASCO, 1990.

BECK, Ulrich. A reinvenção da política: rumo a uma teoria da modernização reflexiva. In: GIDDENS, Antony; BECK, Ulrich; LASH, Scot. Modernização reflexiva: política, tradição e estética na ordem social. São Paulo: Ed., UNESP, 1995.

BECK, Ulrich. Autodissolução e auto-risco da sociedade industrial: o que isso significa? In: GIDDENS, Antony; BECK, Ulrich; LASH, Scot. Modernização reflexiva: política, tradição e estética na ordem social. São Paulo: Ed., UNESP, 1995.

BECK, Ulrich. La sociedad del riesgo global. Madrid: Siglo Veintiuno de España Editores, 2002.

BECK, Ulrich. La sociedad del riesgo: hacia una nueva modernidad. BarceIona-Buenos Aires-México: Paidós, 1998.

BUSS, Paulo Marchiori. Globalization and disease: in an unequal world, unequal health. Cadernos de Saúde Pública, Rio de Janeiro, v.18, n. 6, p. 17831788, nov./dez. 2002.

CASTELLANOS, Pedro Luis. Epidemiologia, saúde pública, situação de saúde e condições de vida: considerações conceituais. In: BARATA, Rita Barradas. (Org.) Condições de vida e situação de saúde. Rio de Janeiro: ABRASCO, 1997.

FORATTINI, Osvaldo Paulo. Epidemiologia geral. Porto Alegre: Artes Médicas, 1986.

GIDDENS, Antony. A vida em uma sociedade pós-tradicional. In: GIDDENS, Antony; BECK, Ulrich; LASH, Scot. Modernização reflexiva: política, tradição e estética na ordem social. São Paulo: Ed., UNESP, 1995.

HARAWAY, Donna. Simians, cyborgs and women: the reinvention of nature. London: Free Association Books. 1991.

LASH, Scott. A reflexividade e seus duplos: estrutura, estética, comunidade. In: GIDDENS, Antony; BECK, Ulrich; LASH, Scot. Modernização reflexiva: política, tradição e estética na ordem social. São Paulo: Ed., UNESP, 1995.

LUHMANN, Niklas. El concepto de riesgo. In: Sociología del riesgo. México: Universidad Iberoamericana; Triana Ed., 1998.

LUIZ, Olinda do Carmo; COHN, Amélia. Sociedade de risco e risco epidemiológico. Cadernos de Saúde Pública, Rio de Janeiro, v. 22, n. 11. p. 4. Disponível em: <http://www.scielo.br/scielo.php>. Acesso em: 11 dez. 2006.

POSSAS, Cristina A. Social ecosystem health: confronting the complexity and emergence of infectious diseases. Cadernos de Saúde Pública, Rio de Janeiro, v. 17, n. 1, p. 31-41, jan./fev. 2001. 